Vo1. 1, No, 1, 2013, 1-9

DOI: $10.11634 / 232907811301268$

\title{
Gender Gap in Most Vulnerable Population in India
}

\author{
Barun Kumar Mukhopadhyay \\ Population Studies Unit, Indian Statistical Institute, Kolkata, India
}

\begin{abstract}
Gender bias of some particular section of population is nowadays regarded as an important social issue especially in developing countries. It is overwhelmingly observed mercilessly killing of female fetus even in high societies so on to the extent of young girls where rampant practice of trafficking is happening particularly in some pockets by the so called international agencies. Atrocities of female children starts right from the household level to overall societies where they are considered as economic burden even if they have for long time come under the purview of international bodies like UNICEF, WHO, World Bank and others. The present paper tries to investigate some of the important classifications in regard to the extent and variation of gender issues of population of vulnerable age below 15 years in India. The study analyses the data from the Censuses, National Sample Survey Organization and Sample Registration System of India for various years and tries to see the extent of dissimilarity between male and female children right from their early lives, missing numbers in census, status of health, education and child employment over time. An index of dissimilarity (ID) has been used to facilitate the analysis of the data. The study shows that significant gender difference existed in some cases or did not in others in the past. Presently there seem to exist both balance and imbalance between the two sexes in so far as the present data are concerned.
\end{abstract}

Keywords: gender, population, infant mortality, dropouts, child employment

\section{Introduction}

Gender issues came in the limelight for the last couple of years especially in developing world. Females have long been attacked in many field of social evils and a recent remark was made about 'demographic terrorism' which in turn is motivated by 'demographic fundamentalism' which reflects the deep-rooted son-complex in Indian society (as in many other societies around the world). The son complex cannot be changed by academic arguments or newspaper advertisements. One may legitimately ask: the son complex has always been there but why should this be responsible for female feticide now by Bose (2007).

A recent paper on gender issue (Mukhopadhyay \& Majumdar, 2012) attempted to find the disparities between overall male and female population of India. As is well known atrocities of inter sex disparities start right from female feticide, abortions to trafficking particularly of young girls. The present paper is to study the differentials among the two sexes of vulnerable age below 15 years in India in respect of various socio economic demographic characteristics on the basis of some restrictive information available from different secondary sources. The National Plan of Action for the Girl Child : 1991 - 2000 and National Policy for the Empowerment of Women 2001 have been initiated by the Government of India to ensure advancement, development of girl children in addition to empowerment of women. It is well known that the Indian constitution guarantees to all citizens equality of status and opportunity and article 15 expressly "prohibits any discrimination" (UN, 1982), girls still receive less health care than boys as variously pointed out in many literatures (Ghosh, 1987; Mukhopadhyay, 1996). Usually girls are less likely to receive medical care than boys, less likely to be admitted to hospital for treatment, and, in some instances, less likely to survive illnesses than boys. The poor nutritional status of girls and women means that their illnesses are of longer duration (Primo, 2003). Moreover, the ultimate adverse effect of such recklessness of the society will be of many fold in demographic determinants such as high incidence of underweight sickly babies, still births, infant, child and consequent mal nutritious unhealthy mothers to die during child birth and puerperium pregnancies. With the emergence of techniques of pre- natal sex detection, first with amniocentesis and later with the help of sonographic scans, selection of sex became an easy task in the last two decades. Recent research has, therefore, looked at sex selective abortions as a major factor causing imbalance in India's sex ratio especially at young ages. This calls for an assessment of the numbers of 'missing girls' and sex selective abortions (Kulkarni, 2007). Estimates of the number of sex-selective abortions for Punjab show, as

ISSN 2329-0781 Print/ ISSN 2329-079X Online/ World Scholars http://www.worldscholars.org 
expected, a very high incidence, over 20 thousand per year in the 1980s rising to over 40 thousand annually since the 1990s. This amounts to about 10 percent of female births in the 1980s and over 20 percent during 2001-05, more than three times the level for India as a whole and even higher than the level estimated for China (Cai \& Lavely, 2003). A detailed gender development index and other development indicators are available (UNDP, 2002) but they consider only overall population, especially in some cases population ages above 15 years which have no connection with the present study on children (population $<15$ years). There has been an overall decline in the labour force participation of children in the 1970s and 1980s but this has been more pronounced for male children such that the rates of child labour force participation (as conventionally measured) are equalizing. However, these do not include girls' domestic labour responsibilities. According to official estimates, child labour still affects up to one quarter of rural children. In certain sub-sectors, such as factory employment, there is some evidence that girl child labour is increasing in India (UK, 1995).

\section{Methodology}

The gender differential of children below the age of 15 years is measured through boys-girls ratio of each subject under study. An Index of Dissimilarity (ID) is developed to examine the differential either as an aggregate of age or over the years.

Index of Dissimilarity $=\frac{\mathbf{1}}{\boldsymbol{n}} \sum\left|\boldsymbol{R}_{x}-\mathbf{1}\right|$

where, $R_{\mathrm{x}}=$ boys / girls at $\mathrm{x}, \mathrm{x}$ is sometimes age or calendar year, $R_{\mathrm{x}}$ is assumed to be Dissimilarity Coefficient (DC) in this paper at individual level, $\mathrm{n}=$ total number of observations.

The minimum value of the index of dissimilarity (ID) is 'zero' indicating no difference between boys and girls. The value above 'zero' indicates the extent of differences in absolute term.

\section{Results}

There are four broad headings under study namely; Population differentials, Health status Literacy status and child labour out of which the following sub classifications are made as follows:

-Population differentials: Population size, Incidence of births and Individual sex-ratios

-Health status: Infant mortality, Age-specific mortality rate and Expectation of life at birth.

-Literacy status: Percentage of literates and Drop outs -Child employment: Labour force participation for 514 years of age in rural and urban areas

\section{Population differentials}

\section{Population size}

The Table 1 represents the disparities of population under 15 years of age in very young, young and older young categories of boys and girls over five decades from 1961 to 2001, Indian censuses. The last column shows the dissimilarity indices over age groups 0-4, 5-9 and 10-14. And the same are calculated over 1961 to 2001 in the last row. The figures clearly show the boys outnumbering the girls in both the cases. And the trend goes up for the under 15 population over the years. Apparently the disparity between the two shows closing towards zero in the very young population rather than other age groups, but the DC values for this group increases over the years. This picture shows that over time females are outnumbered by males. In this regard, National survey data from 1990 found evidence of lower medical contact rates of female than male children and that female children were the most disadvantaged group in the household in this respect. The states with the largest gender differentials in medical contact rates were Orissa, Haryana and Punjab. Other smaller-scale studies have shown that female children are only one third of total children attending outpatient facilities; and only 16.5 percent of children admitted to hospital. Of those who are admitted, girls are more likely than boys to die, suggesting that they are only brought to hospital at an advanced stage of illness. However, survival chances of girls vary by birth order: whilst first sons and first daughters had roughly equal chances, the second plus daughter was at much greater risk, indicating selective neglect as between female children (Premi, 2001).

Table 1. Boys/Girls of Indian Population over the years

\begin{tabular}{cllllll}
\hline Age-group & \multicolumn{5}{c}{ Census year } & \\
\cline { 2 - 6 } & 1961 & 1971 & 1981 & 1991 & 2001 & ID \\
\hline $0-4$ & 1.008 & 1.022 & 1.023 & 1.047 & 1.071 & 0.071 \\
$5-9$ & 1.047 & 1.061 & 1.063 & 1.066 & 1.084 & 0.084 \\
$10-14$ & 1.141 & 1.131 & 1.114 & 1.111 & 1.108 & 0.108 \\
ID & 0.065 & 0.071 & 0.067 & 0.075 & 0.088 & \\
\hline
\end{tabular}


Incidence of births

To have a more clear idea about it we have also computed the sex ratios at births since 1981-83 to 19982000 from Sample Registration Data of India (Table 2). The data indicate male births outnumbering female births and the degree of differences are much higher than the international figure of (104-106) male births per 100 female births over the entire time period of 1981 to 2000. Although male births outnumber female births but up to a certain extent. At early periods the differentials might have happened because of natural process apart from some probable amount of female undercounting but over time there seem to be an indication of bias towards male birth may be because of several reasons one may quote as son preference experiences one may gain. Now people have many options available in order to have their choice able sex determinations before delivery to their spouses. Accordingly female feticide and/or sex selective abortions are common for the last couple of years about which observation made by Kulkarni (2007) is already made and worth mentioning here. Now, a resort may be made to the next section about the disparity of health status among boys and girls.

Table 2. Male-Female birth ratio in India.

\begin{tabular}{cl|l|l}
\hline Year & DCs & Year & DCs \\
\hline $1981-1983$ & 1.09 & $1988-1990$ & 1.10 \\
$1982-1984$ & 1.10 & $1989-1991$ & 1.10 \\
$1983-1985$ & 1.10 & $1990-1992$ & 1.11 \\
$1984-1986$ & 1.10 & $1991-1993$ & 1.12 \\
$1985-1987$ & 1.10 & $1992-1994$ & 1.11 \\
$1986-1988$ & 1.10 & $1993-1995$ & 1.11 \\
$1987-1989$ & 1.10 & $1998-2000$ & 1.11 \\
\hline \multicolumn{3}{l}{ Index of Dissimilarity (ID) } \\
\hline \multicolumn{5}{l}{ Source: Office Registrar General India. }
\end{tabular}

\section{Individual sex-ratios}

Apart from if any under counting error in the data, there seem to be an indication of attitudinal difference of the population about the sex bias over the five decades in the sense that sex ratios at very early ages increase from 1961 onwards 2001. As time goes on couples' desire for male babies is also highly demanded. This is quite tallying with the other studies as mentioned earlier. On the other hand, the pattern of high sex-ratios at later ages at 12, 13 and 14 , in particular may indicate of the suppression of unmarried girl children at the time of census in order not to face marriage problem in uneducated families.

This is also a kind of gender bias because male children face no such problems in the society. A kind of fear may prevail in remote villages or urban slums in reporting particularly young girls at the time of census or any kind of survey because of high incidence of girl trafficking is happening in the country.

The index of dissimilarity is found to decline from 0.040 to 0.016 during early ages from 0 to 3 . This may possibly be due to female infanticide and child death due to improper care of girl child. The table shows in both the cases once considering age and secondly over the years, the ID values more or less increase thereby showing gender discrimination for the young population in India rising to a certain extent that is what is exactly commented as 'missing girl child' as variously pointed out by many social scientists and demographers. In the next section, the most important aspects of health of the child is continued.

Table 3. Sex-ratios at single ages from 0 to 14 during 1961to 2001, India.

\begin{tabular}{ccccccc}
\hline Single Age & \multicolumn{1}{c}{1961} & 1971 & 1981 & 1991 & 2001 & ID \\
\hline 0 & 1.01 & 1.01 & 1.03 & 1.06 & 1.09 & 0.040 \\
1 & 1.00 & 1.02 & 1.03 & 1.07 & 1.09 & 0.042 \\
2 & 1.02 & 1.03 & 1.02 & 1.04 & 1.07 & 0.036 \\
3 & 0.99 & 0.99 & 0.99 & 1.02 & 1.03 & 0.016 \\
4 & 1.03 & 1.05 & 1.05 & 1.06 & 1.08 & 0.054 \\
5 & 1.07 & 1.08 & 1.09 & 1.11 & 1.12 & 0.094 \\
6 & 1.06 & 1.06 & 1.06 & 1.06 & 1.07 & 0.062 \\
7 & 1.02 & 1.03 & 1.04 & 1.04 & 1.07 & 0.040 \\
8 & 1.06 & 1.08 & 1.08 & 1.07 & 1.09 & 0.076 \\
9 & 1.02 & 1.04 & 1.04 & 1.05 & 1.07 & 0.044 \\
10 & 1.11 & 1.10 & 1.10 & 1.12 & 1.13 & 0.112 \\
11 & 1.06 & 1.06 & 1.08 & 1.10 & 1.11 & 0.082 \\
12 & 1.23 & 1.21 & 1.17 & 1.14 & 1.13 & 0.176 \\
13 & 1.13 & 1.10 & 1.07 & 1.06 & 1.06 & 0.084 \\
14 & 1.16 & 1.15 & 1.11 & 1.11 & 1.10 & 0.126 \\
ID & 0.066 & 0.069 & 0.065 & 0.074 & 0.087 & \\
\hline
\end{tabular}




\section{Health Status}

\section{Infant mortality}

The male-female infant mortality rates from 1985 to 2000 are given in Table 3 along with the DCs. The values of IMF are declining in both the cases of sexes more or less over the entire period from 1985 to 2000. The CIA World Fact book (Network system, 2011) shows, male: 46.18 deaths $/ 1,000$ live births and female: 49.14 deaths/1,000 live births in India, 2011. From these figures the value of DC in 2011 is found to be 0.940 which is still not favouring females. From the table the ratios are found higher than unity in some stray cases where female mortality is less, otherwise in most years the values indicate higher infant mortality rates among females than males. And the overall index of dissimilarity of 0.024 signifies more female infant deaths than males, although the value is not very significant. In this regard once an observation was made by Das Gupta (1987): It may rightly be mentioned here that gender inequality in seeking health care is documented from an early age. It is evident that among children, boys are more likely to receive health care early in their illness and to receive better quality care from qualified doctors instead of local quacks; and expenditure on medicine is also greater in the case of boys than girls.

Table 3. Infant mortality rates by sex per thousand live births and male-female ratio of infant mortality rates for India over the years.

\begin{tabular}{llcc}
\hline Year & Male & Female & DCs \\
\hline 1985 & 96 & 98 & 0.980 \\
1986 & 96 & 97 & 0.990 \\
1987 & 95 & 96 & 0.990 \\
1988 & 95 & 93 & 1.022 \\
1989 & 92 & 90 & 1.022 \\
1990 & 78 & 81 & 0.983 \\
$1991^{\text {a }}$ & 81 & 80 & 1.013 \\
$1992^{\text {a }}$ & 79 & 80 & 0.988 \\
$1993^{\text {a }}$ & 73 & 75 & 0.973 \\
$1994^{\text {a }}$ & 75 & 73 & 1.027 \\
$1995^{\text {a }}$ & 73 & 76 & 0.961 \\
1996 & 71 & 73 & 0.973 \\
1997 & 70 & 73 & 0.959 \\
1998 & 70 & 69 & 0.986 \\
1999 & 67 & 68 & 0.971 \\
2000 & 64 & & 0.941 \\
\hline Index of dissimilarity (ID) & \multicolumn{3}{c}{} \\
Source: Sample Registration System (various years), Office of the Registrar General, India \\
: Excludes Jammu \& Kashmir
\end{tabular}

Age-specific mortality rate

Boys/girls ratios of age specific mortality rates are presented in Table 4. The differentials in male-female ratios of the age-specific mortality rates have been systemically increasing in the two age groups, 0-4 and 5-9 for the last couple of years indicating some improvement on the part of girls, although their rates are higher than boys. This has an indication of neglect of infant and child (5-9) girls. But after that the death rates for boys are becoming higher than girls which are unusual. However this phenomenon is not implied by the ID values

Table 4. Boys/girls ratios of age specific mortality rates by quinquennial age groups for India 1971-2001.

\begin{tabular}{|c|c|c|c|c|c|}
\hline \multirow[t]{2}{*}{ Age group } & \multicolumn{4}{|c|}{ Year } & \multirow{2}{*}{$\begin{array}{c}\text { Index of } \\
\text { Dissimilarity }\end{array}$} \\
\hline & 1971 & 1981 & 1991 & 2001 & \\
\hline $0-4$ & 0.898 & 0.905 & 0.931 & 0.893 & 0.093 \\
\hline $5-9$ & 0.918 & 0.841 & 0.897 & 0.900 & 0.109 \\
\hline $10-14$ & 1.000 & 1.059 & 0.875 & 1.083 & 0.067 \\
\hline ID & 0.061 & 0.104 & 0.099 & 0.097 & \\
\hline
\end{tabular}


The combined result is that girls are less likely to receive medical care than boys, less likely to be admitted to hospital for treatment, and, in some instances, less likely to survive illnesses than boys. The poor nutritional status of girls and women means that their illnesses are of longer duration (Primo, 2003).

\section{Expectation of life at birth}

The expectation of life at births for males and females and male-female ratios of expectation of life at births are shown in Table 5. The expectation of life at births for both males and females have an increasing trend. Given the phenomenon that agespecific female mortality rates are less, particularly at advanced ages the male-female ratios of the life expectancy at birth show the fifty-fifty position. Whereas better position may be said for males during 1921 to 1980 , females show similar pictures during 1901 to 1921 and again during 1981 to 1991. However, the overall difference in expectation of life at birth over the years as indicated by index of dissimilarity is 0.023 which simply shows the overall better position as far as males are concerned. There may be more argument about the trend of figures in the table showing zigzag picture.

Table 5. Male-Female ratio of expectation of life at birth (in years) for India over the years.

\begin{tabular}{lccc}
\hline Year & \multicolumn{3}{c}{ Expectation of life at birth (in years) } \\
\cline { 2 - 4 } & Male & Female & DCs \\
\hline $1901-1911$ & 22.6 & 23.3 & 0.970 \\
$1911-1921$ & 19.4 & 20.9 & 0.928 \\
$1921-1931$ & 26.9 & 26.6 & 1.011 \\
$1931-1941$ & 32.1 & 31.4 & 1.022 \\
$1941-1951$ & 32.4 & 31.7 & 1.022 \\
$1951-1961$ & 41.9 & 40.6 & 1.032 \\
$1961-1971$ & 46.4 & 44.7 & 1.038 \\
$1970-1975$ & 50.5 & 49.0 & 1.031 \\
$1976-1980$ & 52.5 & 52.1 & 1.008 \\
$1981-1985$ & 55.4 & 55.7 & 0.995 \\
$1987-1991$ a & 58.1 & 58.6 & 0.991 \\
$1991-1995$ a & 59.7 & 60.9 & 0.980 \\
1995-1999 & 60.8 & 62.5 & 0.973 \\
\hline Index of Dissimilarity (ID) & & 0.023 \\
\hline Source: Office of the Registrar General India & & \\
: Excludes Jammu \& Kashmir & & & \\
Notes : Figures for 1901-11 to 1961-71 are based on Census Actuaries Reports and for 1970-75 on wards are based on the \\
estimates from Sample Registration System.
\end{tabular}

\section{Literacy Status}

\section{Percentage of literates}

Status of literacy of the boys and girls are studied in terms of percentage of literates and next in terms of dropouts. It is very important aspect of social life in order to eradicate superstitions, unscientific customs and beliefs and improving the health and economic conditions of the people in the society. Literacy rate or percentage of literates is defined as the number of literate population per hundred eligible population. The ratios of boys and girls of literacy rates are found declining in both the age groups of 5-9 and 10-14 years for all the years since 1961 to 2001 but still the gap is significantly much high (Table 6). The difference is much higher among population aged 1014 years as compared to 5-9 years. This may possibly be due to dropouts of girls of higher ages. From the ID values in the last column of the table there seem to be dissimilarities in 5-9 and 10-14 which may possibly be due to less enrollment for girls at lower age group. And the increase of dissimilarity from lower to higher ages may be because of girls at higher ages dropout from the schools. Although the ID values in the last row show a declining trend from 0.830 to 0.105 over the five decades, still efforts seem to be necessary to control over dropouts of girls at ages 1014 years. A mention may be made about Primo (2003) said : 2003 Millions of children in India, but particularly girls, never attend school or drop out soon after initial enrolment. Considerable efforts are being made to increase girls' access to education but the relative contribution of different interventions to increasing female enrolment is poorly understood.

There has been considerable work on revising the curriculum in India, including from a gender perspective, e.g. by making textbooks more girlfriendly. The revision of text books needs to go beyond the addition of more positive images of women and girls to incorporating discussions of gender discrimination. Other kinds of bias which interact with gender biases also need to be addressed in educational materials - e.g. caste and communal 
biases. There is also a need to address the .hidden curriculum. Which contributes significantly to reproducing gender disparities, e.g. teacher-pupil interaction, staff hierarchies, extra-curricular options and so on. There has been considerable work on revising the curriculum in India, including from a gender perspective, e.g. by making textbooks more girl-friendly. The revision of text books needs to go beyond the addition of more positive images of women and girls to incorporating discussions of gender discrimination. Other kinds of bias which interact with gender biases also need to be addressed in educational materials - e.g. caste and communal biases. There is also a need to address the .hidden curriculum which contributes significantly to reproducing gender disparities, e.g. teacher-pupil interaction, staff hierarchies, extra-curricula options and so on (UK, 1995). In girl schools toilet facilities may help reduce dropouts. While advocacy for gender issues in ICTs gained their first international foothold at the fourth World Conference on Women in Beijing in 1995, the issue of gender issues in ICT policy has been on the international scene for only four years. It first came into international consciousness with a series of papers on gender issues, particularly in policy, presented at the World Telecommunications Development Conference organized in Valletta, Malta under the auspices of International Telecommunication Union (ITU). Engendering ICT policy is an area of great importance, perhaps the most important in securing the benefits of the information age for girls and women. If gender issues are not articulated in ICT policy, it is unlikely that girls and women will reap the benefits of the information age (Hafkin, 2002). In terms of using computers in public place girls are feeling unsafe even in modern times. The children do not perceive computers in schools as their property and playthings. They suspect some hidden agenda and are afraid of some "catch" in using them. Girls tend to avoid going into closed rooms with boys, unless there is some adult supervisor. In most outdoor locations, the number of girls and boys are about equal. However, there are some locations, particularly in slums and very poor areas, where there are very few girl users. Ensuring and perceiving safety is important for attracting girls to public computers (Mitra, 2004).

Table 6. Boys/girls ratios of literacy rates over the years, India.

\begin{tabular}{ccccccc}
\hline Age & \multicolumn{7}{c}{ Year } & ID \\
\cline { 2 - 6 } & 1961 & 1971 & 1981 & 1991 & 2001 & 0.372 \\
\hline $5-9$ & 1.74 & 1.44 & 1.36 & 1.23 & $1.09 *$ & 0.478 \\
$10-14$ & 1.92 & 1.57 & 1.49 & 1.29 & 1.12 & \\
ID & 0.830 & 0.505 & 0.425 & 0.260 & 0.105 & \\
Source: Office of the Registrar General, census of India (various years). \\
* Indicates age group 7-9 years
\end{tabular}

\section{Dropouts}

Dropout rate is defined as the proportion of children that cease to remain enrolled in the schooling system. There are a number of methods for estimating dropout rate. One of them, followed in the Selected Education Statistics (SES) of the Ministry of Human Resource Development, is as follows:

Gross dropout rates for classes (I-V) $=\{1$-(Enrolment in Class $\mathrm{V}$ during the reference year divided by the enrolment in Class I four years ago) $\} * 100$.

Gross dropout rates for classes $(\mathrm{I}-\mathrm{VIII})=\{1$ (Enrolment in Class VIII during the reference year divided by the enrolment in Class I seven years ago) ${ }^{*} 100$. Enrollment of the child in school is a necessary condition so that the question of dropout comes. In the present paper the emphasis is given for dropout rather than enrollment because it is the prima face object of the parents to get their children admitted into the school. But the important matter is to see whether they remain enrolled in the schooling system. Moreover reason for non enrollment is superseded by dropout which has many fold reasons. As a result the following table is produced for the gender disparities in respect of dropouts in India over some period of years.

Table 6: Boys/girls ratios of dropouts separately for classes I-V and I-VIII with IDs over the years, India

\begin{tabular}{lccccccc}
\hline Stage & $1999-2000$ & $2000-2001$ & $2001-2002$ & $2002-2003$ & $2003-2004$ & $2004-2005$ & ID \\
\hline Class I-V & & & & & & & \\
Boys & 38.7 & 39.7 & 38.4 & 35.9 & 33.7 & 31.37 \\
Girls & 42.3 & 41.9 & 39.9 & 33.7 & 28.6 & 24.82 & \\
Boys/ Girls & 0.914 & 0.947 & 0.962 & 1.065 & 1.178 & 1.264 & 0.114 \\
ID & 0.086 & 0.053 & 0.038 & 0.065 & 0.178 & 0.264 & \\
Class I-VIII & & & & & & & \\
Boys & 52.0 & 50.3 & 52.9 & 52.3 & 51.8 & 50.10 & \\
Girls & 58.0 & 57.7 & 56.9 & 53.4 & 52.9 & 50.76 & \\
Boys/ Girls & 0.897 & 0.872 & 0.930 & 0.979 & 0.979 & 0.987 & 0.173 \\
ID & 0.103 & 0.128 & 0.070 & 0.021 & 0.021 & 0.031 & \\
\hline
\end{tabular}


The above table shows the dropout ratios between boys and girls in two stages of schooling, I-V and IVIII over six decades from 1999 to 2005. First of all in primary level the disparities between boys and girls slowly narrow down from 0.086 in 1999-2000 to 0.038 in 2001-2002. After 2002 the gap is observed to increase till 2005. This trend is because of dropouts of independent values of trend in dropout rates of boys and girls at varying rate. Otherwise both of them show decline in their respective rates over six decades. The remarkable features may be noted as the girls go on higher stage of education where the picture is encouraging as far as development status of females are concerned. The dropout rates for them have drastically declined from 58.0 in 1999-2000 to 50.76 in 2004-2005. On the other hand the level for the boys stands more or less around fifty per cent. The ID values are more or less found slowly declining over the period. While comparing the dropouts between the two stages it may be said that index of dissimilarity is slightly higher in higher stage that is class I-VIII. There may be some reason why girls at higher ages tend to dropout more than their boys counterpart. This picture may prevail in rural areas in India where security of the young girl is no doubt a cause. Moreover, GOI is trying now to build some ladies toilet in the school so that dropout can be checked. Apart from this, age at marriage though it is 18 for girls and 21 for boys in India, parents usually are in favour of early marriage of their daughters. But in some countries there are different kinds of attitude of the population towards girls education. This is clear from the gloomy pictures prevailing about girls or women in developing countries like Africa and some Pacific countries. To quote, " Many (predominantly male) math and science teachers in Africa hold outmoded views that girls can't think or work scientifically and that science is too mechanical and technical for girls, thus discouraging female students" (Quaisie, 1996). "In some Pacific countries (especially those of Melanesia) traditional cultural attitudes discriminate against women having access to education and technology. Girls are encouraged to take any job or get married rather than seek higher education. The alternative of doing two (or three!) things at the same time is not realistically entertained (Commonwealth of Learning 2001a: 28). Attitudes that information technology is not for women are not limited to formal education. In an ITDG project for farmers in Cajamarca, Peru, when women undertook information technology training with men, the men mocked them, saying that computers were for men, not women (Puican 2002)".

\section{Child employment}

Labour force participation for 5-14 years of age in rural and urban areas Women's involvement in various fields of economic activities is necessary for empowering them. But it is not true while they are in schooling age. The work force participation rate is defined as the ratio of total workers i.e., principal status and subsidiary status to total eligible persons (i.e., persons available for work). The gender differentials in participation rates in the labour force are calculated through boys/girls ratios of the same.

Table 7. Labour force participation rates and DCs for boys and girls in rural and urban India.

\begin{tabular}{|c|c|c|c|c|c|c|}
\hline & \multicolumn{3}{|c|}{ Labour force participation rate } & \multicolumn{3}{|c|}{ Labour force participation rate } \\
\hline & \multicolumn{3}{|c|}{ Rural } & \multicolumn{3}{|c|}{ Urban } \\
\hline & Boys & Girls & $\mathrm{DC}$ & Boys & Girls & $\mathrm{DC}$ \\
\hline $1977-78$ & 13.1 & 9.1 & 1.440 & 5.8 & 3.8 & 1.526 \\
\hline 1983 & 11.6 & 9.0 & 1.289 & 5.6 & 3.0 & 1.867 \\
\hline $1987-88$ & 7.4 & 6.3 & 1.175 & 4.2 & 2.4 & 1.750 \\
\hline 1993-94 & 5.9 & 5.5 & 1.073 & 3.3 & 1.9 & 1.737 \\
\hline
\end{tabular}

Table 7 presents the boys/girls ratio of work force participation rates over the years in India. The boys/girls work force participation gap is much more wide in urban areas in comparison with rural areas. There is clear declining trend in the values in the ratios of the participation rates both in rural as well as urban areas. Less number of girls is involved in economic activity in comparison with their boys counterpart as the ratios are greater than 1 for all the cases. However the gap between them is slowly reducing both in rural and urban areas. This may perhaps be due to more engagement of girls in economic activity rather than boys particularly in rural areas where they use to assist in household agricultural activities.

\section{Conclusion}

Gender bias of young children of vulnerable age under 15 years is the topic of the present paper. There 
may be several factors through which the study may be conducted. The present attempt is made on the basis of the availability of data from different sources as mentioned in the earlier paragraph. As the study conducted on different aspect at a time, hence the conclusion is made according to that order. First of all, the disparities are observed of population under 15 years of age in three categories, very young, young and older young of boys and girls over five decades from 1961 to 2001, Indian censuses. The study shows the boys outnumbering the girls which is now a days called as "missing girls" in different literatures. And the trend goes up over the years from 1961 to 2001. This might have happened if the analysis is done between the two in terms of infant mortality which also indicates disparities, but not throughout the decades wherein sometimes male deaths are higher than females. But overall there is gap which is favouring males. The differentials in male-female ratios of the age-specific mortality rates have been systemically increasing in the two age groups, 0-4 and 5-9 for the last couple of years indicating some improvement on the part of girls. However this phenomenon is not implied by the ID values which indicate overall bias towards males.

The expectation of life at births for both males and females have an increasing trend. Given the phenomenon that age-specific female mortality rates are less, particularly at advanced ages the malefemale ratios of the life expectancy at birth show the fifty-fifty position. Whereas better position may be said for males during 1921 to 1980 , females show similar pictures during 1901 to 1921 and again during 1981 to 1991. However, the overall difference in expectation of life at birth over the years as indicated by index of dissimilarity is 0.023 which simply shows the overall better position as far as males are concerned. And in turns the same situation may be said for boys.

Status of literacy of the boys and girls are studied in terms of percentage of literates and next in terms of dropouts.

It is very important aspect of social life in order to eradicate superstitions, unscientific customs and beliefs and improving the health and economic conditions of the people in the society. The ratios of boys and girls of literacy rates are found declining in both the age groups of 5-9 and 10-14 years for all the years since 1961 to 2001 but still the gap is significantly much high. The difference is much higher among population aged 10-14 years as compared to 5-9 years. This may possibly be due to dropouts of girls of higher ages. From the ID values there seem to be dissimilarities in 5-9 and 10-14 which may be due to less enrollment for girls at lower age group.
Although dropout rates for girls have declined during 1999 to 2005, but the same for boys did not happen, rather remained stable over the same period. The interesting thing is that the index of dissimilarity in middle standard of education is higher than primary level thereby indicating higher dropouts of girls in middle standard. This is what the mentality of the uneducated parents not to allow young girls to move outside their premises especially in rural areas. As the major population of India reside in rural regions, their effect is shown in the entire country.

Finally the labour force participation of young children of ages 5 to 14 years of age has been studied separately for rural and urban sectors. It all depends as far as the data are available. The rates are found less for both in urban areas as compared to rural areas throughout the period of study. In rural areas agricultural activities are very common both for land owner and labourer. While comparing the gap between boys and girls, urban areas show a slightly higher value than rural areas. It is more common that boys are found in many tea stalls, restaurants and other unorganized sectors as child labour. On the other hand girls in villages are usually found to do either agricultural activities in their own land or as labourer in other big land owner, particularly in some poor families.

To sum up it may be argued that first of all the responsibility of the nation and the population at large to look into this particular subject seriously. The children at the moment are the nation's assets who may be expected to take up the responsibility of the future development of the country. They must be properly nourished in respect of their health, education in their early lives, and when they become matured after completing their higher studies mental optimism in them so that they may be quite ready to take up higher, sophisticated and technical jobs. These may all happen if the parents, guardians and the government do sacrifice in their wisdom to build up the nation at a high level of supremacy. International Food Policy Research Institute (IFPRI), USA (2012) opined, " 1,000 day window is one of the best investments on food and nutrition we can make to achieve lasting progress in global health and development". 1,000 day window consists of 273 days of gestation period of mother, the population below one year and below 2 years of age. Their model would be effective, to a great extent if gender bias is eradicated out and out from the societies at large. Last but not the least, there should be responsibilities on the part of the international bodies, self government and NGOs at macro level at the same time the people themselves in the country at micro level to take proactive action immediately. 


\section{Note}

An earlier version was presented at EAPS International Population Conference, Stockholm University, June 16-19, 2012

\section{References}

Bose, Ashish (2007). India's unborn daughters - Victims of demographic terrorism, Key Note Address, National Level Seminar on Gender Issues and Empowerment of Women on the Occasion of Platinum Jubilee of Indian Statistical Institute, Kolkata during 2006-2007.

Cai, Y \& William L. (2003). China's missing girls: Numerical estimates and effects on population growth, The China Review 3(2), 13-29.

Dasgupta, Monica (1987). Selective discrimination against female children in rural Punjab India", Population and Development Review, 13, The Population Council, New York, USA.

Ghosh, S. (1987). Women and young children :Population at high risk, Proceedings of the Eight Annual Conference of the Indian Society for Health Administrator, ed: Shami, A., Madras.

Hafkin, N (2002). Gender issues in ICT policy in developing countries: An overview, information and communication technologies and their impact on and use as an instrument for the advancement and empowerment of women", Division for the Advancement of Women (DAW), United Nations.

Kulkarni, P. M (2007). Missing girls at birth and juvenile ages in India, paper prepared for the United Nations Population Fund (UNFPA), India

Mitra, Sugata (2004). The hole in the wall, Dataquest, Retrieved from: http://www.dqindia.com
Mukhopadhyay, B. K. \& Majumdar P. K. (2011). Status of gender-differentials and trends in India: Population, health, education and employment in Pal, M; Pathak, P; Bharati, P; Ghosh, B; Majumder, A. d.), Gender issues and empowerment of women, Nova Science Publishers, INC., New York.

Mukhopadhyay, B. K (1996). Trends and developments in maternal mortality vis-à-vis a differential health socioeconomic and infrastructural transformation among the major states In India, in B. Roy (ed.) Socio-Economic Transformation in India, Kanishka Publishers, Distributors, New Delhi.

Premi, M. K (2001). The missing girl child, economic and political weekly, Vol. 36, May 26

Primo, N (2003). Gender issues in the information society, UNESCO Publications for the World Summit on the Information Society.

Norma, P (2002). Gender review in the InfoDev Project 'Information Systems for Rural Development: A demonstration Project' in Cajamarca (Peru), Unpublished study prepared for infoDev.

Quaisie, G (1996). Paving the way for girls to achieve excellent in science and math: Science, technology and math education (STME) clinic for girls. Papers $f$ the eighth International Conference of the Gender and Science and Technology Association (GASAT8).

UK (1995). Background report on gender issues in India: Key findings a short report, Report commissioned by the Overseas Development Administration (DFID) Report No. 32.

United States (2012). Nutrition-sensitive interventions: A Study from India, International Food Policy Research Institute (IFPRI).

UNDP (2002). Human development report office, Occasional Papers, New York 10017 